\title{
Carcass composition of Namaqua Afrikaner, Dorper and SA Mutton Merino ram lambs reared under extensive conditions
}

\author{
A. Burger ${ }^{1,2}$, L.C. Hoffman ${ }^{2 \#}$, J.J.E. Cloete ${ }^{2,3}$, M. Muller ${ }^{1}$ \& S.W.P. Cloete ${ }^{2,4}$ \\ ${ }^{1}$ Department of Food Science, Stellenbosch University, Matieland 7602, South Africa \\ ${ }^{2}$ Department of Animal Sciences, Stellenbosch University, Matieland 7602, South Africa \\ ${ }^{3}$ Elsenburg Agricultural Training Institute, Private Bag X1, Elsenburg 7607, South Africa \\ ${ }^{4}$ Institute for Animal Production: Elsenburg, Elsenburg 7607, South Africa
}

(Received 1 October 2012; Accepted 4 April 2013; First published online5 July 2013)

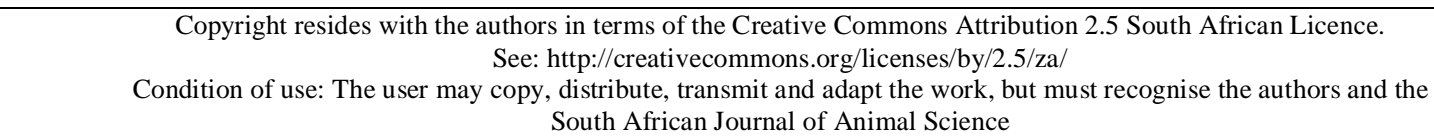

\begin{abstract}
This study evaluated the differences in the muscle-fat-bone yield of Namaqua Afrikaner (NA), Dorper (D) and SA Mutton Merino (SAMM) ram lambs. The breeds constituted an indigenous, hardy and late maturing, fat-tailed breed (NA), an early maturing, commercial meat breed (D) and a late maturing commercial dual-purpose breed (SAMM). Lambs were slaughtered at $35( \pm 8)$ days post weaning. Carcasses were cooled for $24 \mathrm{~h}$, separated into retail cuts (leg, loin, rib, and shoulder), weighed and deboned. Meat and fat were separated after deboning and weighed to calculate the muscle-fat-bone yield per cut. Least-square means were computed for the respective breeds, using slaughter age as covariate. Results for percentage meat indicate that, with exception of the rib, retail cuts from the NA breed contained a lower percentage of meat than D and SAMM breeds, particularly in the valuable loin and leg cuts. The shoulder of the NA had a lower percentage meat than that of the $\mathrm{D}$. The percentage fat in retail cuts did not differ between breeds for any of the cuts. In comparison with both D and SAMM, NA contained a higher percentage bone in all cuts. Dorper and SAMM carcasses did not differ in terms of the percentage of bone, fat or muscle for any of the retail cuts. The lower meat yield, particularly in the more expensive loin and leg of the NA, when compared to the commercial meat breed (D) could make the former less preferred for meat production. However, the NA compared more favourably than the dual-purpose SAMM. Differences in carcass composition could be attributed to the fact that the NA is an unimproved and late maturing sheep breed.
\end{abstract}

Keywords: Muscle-fat-bone yield, indigenous, early-maturing, late-maturing, retail cuts, sheep

\# Corresponding author: lch@sun.ac.za

\section{Introduction}

The largest part of South Africa is located in either an arid or semi-arid region, limiting possible agricultural production to pastoral use (Cloete \& Olivier, 2010). Due to global weather changes tending towards a drier climate in the south-western parts of South Africa, natural food resources for livestock are forecast to diminish (Turpie et al., 2002). This changing scenario is expected to result in challenges to small stock farming as far as adaptation of animals and the sustainability of farming is concerned.

During 2011, South African sheep meat (lamb and mutton) consumption was estimated at 149000 tons. Only 140000 tons were produced within South Africa, clearly indicating a demand for increased and optimised sheep meat production in South Africa (DAFF, 2012; FAO, 2012). Thus, it is evident that the local animal genetic resources should be harnessed optimally to ensure sustainable sheep meat production under variable and often adverse conditions.

Owing to the association between the saturated fatty acids (SFA) found in red meat and the detrimental effects of SFA on human health, consumers prefer leaner meat of younger animals (Warriss, 2000). Coronary heart disease (CHD) and certain cancers, such as colon cancer, have been linked to a high 
dietary intake of SFA (Higgs, 2000; Wood et al., 2003). While meat contains a combination of saturated and unsaturated fatty acids, consumers have made the assumption that all the fatty acids in meat are saturated, deeming red meat as unhealthy and creating a negative association with red meat consumption (Reiser \& Shorland, 1990, as reviewed by Webb et al., 1994).

However, the nutritional benefits of meat is often overlooked (Biesalski, 2005). Meat is considered as a nutrient dense source of micronutrients including selenium, vitamins $\mathrm{A}, \mathrm{B}_{12}$ (only found in animal products) and folic acid, as well as essential amino acids and proteins with high biological value (Warriss, 2000; Biesalski, 2005). Another nutritional attribute of red meat is that it is regarded as one of the best food sources of bioavailable iron, as consumed by humans (Warriss, 1976; 2000; Lawrie \& Ledward, 2006). Meat consumption should thus be balanced as part of a diverse diet, keeping cuts lean with excess fat trimmed (Higgs, 2000; Biesalski 2005).

Three sheep breeds representing a wide spectrum of the local ovine genetic resource were thus studied for their lean meat production potential. These included the Namaqua Afrikaner (NA), an indigenous, hardy and late maturing, fat-tailed breed, the Dorper (D), an early-maturing, commercial meat breed and the late maturing, commercial dual-purpose South African Mutton Merino (SAMM).

The NA is well known for its ability to survive the harsh South African climate (Epstein, 1960). The ancestors of the NA can be traced back to the fat-tailed sheep owned by the northern Namaqua Khoi people and thus it is regarded as a national heritage. The NA has a slender body with long legs, well adapted for walking vast distances in search of food and water. Body fat is mostly accumulated in the fat-tail and fat deposits on the loin are minor (Epstein, 1960). Fat-tailed sheep are well known for their ability to survive in harsh environments. Instead of the subcutaneous layer of fat used for insulation, the adaptive response is to store surplus fat in the tail, with minor fat deposits in the rest of the body. The fat-tail acts as a depot for reserve fat in times of abundance and is utilised when food and water are scarce (Epstein, 1960).

The D is the largest commercially farmed meat breed in South Africa and the second largest sheep breed population overall, contributing $24 \%$ of the weaning weight records to the National Small Stock Improvement Scheme (NSIS) (Cloete \& Olivier, 2010). Dorpers are early maturing sheep, showing excellent carcass characteristics, as well as adaptation to adverse environments (Webb \& Casey, 1995; Brand, 2000).

The SAMM is the main dual-purpose breed (6\% of the NSIS records), farmed for meat and wool (Cloete \& Olivier, 2010). The SAMM has a strong, large body frame with good meat quality attributes e.g. tender meat with a reduced back-fat depth (Cloete et al., 2005). It is a late maturing breed and thus meat of the SAMM should have less fat than that of the D if slaughtered at the same chronological age (Van der Westhuizen, 2010).

The main objective of the study was to assess the indigenous, unimproved NA against the two commercial breeds (D and SAMM) in terms of the quantity of meat yielded.

\section{Materials and Methods}

Twenty nine male lambs of the NA $(n=13), D(n=10)$ and SAMM $(n=6)$ breeds were randomly selected from the flock on the Nortier Experimental farm (32 $02^{\prime} \mathrm{S}$ and $18^{\circ} 20^{\prime} \mathrm{E}$ ), situated in the West Coast Strandveld, South Africa. The area's typical weather can be described as Mediterranean, with hot dry summers and cold winters. About 76\% of the total long-term annual precipitation of $221 \mathrm{~mm}$ is recorded during winter (April - September) (Cloete et al., 2005). Vegetation on the Nortier Experimental farm is type 34 - Strandveld as described by Acocks (1988), to which the lambs had ad libitum access.

Lambs were slaughtered according to standard South African procedures (Hoffman et al., 2003) at 35 $( \pm 8)$ days post weaning, averaging slaughter weight of $17 \mathrm{~kg}$ for both $\mathrm{D}( \pm 2.31)$ and SAMM $( \pm 2.14)$ and 10 $\mathrm{kg}( \pm 2.27)$ for NA. Thirty minutes after slaughtering, dressing and evisceration, the carcasses were weighed to obtain hot carcass weight (HCW). After being cooled down for $24 \mathrm{~h}\left(4{ }^{\circ} \mathrm{C}\right)$ the kidneys and channel fat were removed and weighed to obtain cold carcass weight. The carcasses were divided into the four retail cuts (leg, loin, rib, shoulder). The entire carcass of each lamb was analysed. Each retail cut (x 2 per carcass) was weighed and deboned. Meat and fat were separated by dissection and weighed. From these results musclefat-bone percentage yield was calculated as the weight of the tissue expressed as a percentage of the cold dressed carcass weight. It is important that the correct analytical method is used to assess muscle-fat-bone yield in sheep. Since only minor fat deposits are expected in the loin of the NA, the composition of the threerib cut would not be an accurate reflection of the NA carcass. 
An analysis of variance involving the general linear models (GLM) procedure of SAS (2002) was conducted on the different traits (percentage bone, percentage meat and percentage fat). Least square means (LSM) values were calculated and used to correct for the unbalanced data. R-square Type III P-values were used to test for significant differences. Results were corrected with slaughter age (153 \pm 12 days) as covariant and a significance level of $95 \%$ was used as basis for all calculations.

\section{Results and Discussion}

No differences $(P>0.05)$ were found between the breeds for percentage of fat and percentage of bone, when comparing the results of the complete carcasses (Table 1). This concurs with previous research where no differences were found between D and SAMM carcasses in terms of percentage bone and fat yield (Webb \& Casey, 1995). Results for percentage meat indicated that the carcass of the NA contained less $(P \leq 0.05)$ meat than D and SAMM carcasses. No differences $(P>0.05)$ were found between the D and SAMM carcasses.

Table 1 Least square means ( \pm SE) of percentage muscle-fat-bone yield of the NA, D and SAMM carcasses

\begin{tabular}{llll}
\hline \multirow{2}{*}{ Yield } & \multicolumn{2}{c}{ Breed } \\
\cline { 2 - 4 } & NA $(\mathrm{n}=13)$ & $\mathrm{D}(\mathrm{n}=10)$ & SAMM $(\mathrm{n}=6)$ \\
\hline Percentage meat & $44.8^{\mathrm{b}} \pm 0.81$ & $51.3^{\mathrm{a}} \pm 0.91$ & $51.3^{\mathrm{a}} \pm 1.21$ \\
Percentage fat & $10.5 \pm 0.85$ & $13.9 \pm 0.96$ & $12.5 \pm 1.28$ \\
Percentage bone & $32.3 \pm 2.46$ & $29.8 \pm 2.78$ & $27.9 \pm 3.68$ \\
\hline Average carcass weight $(\mathrm{kg})$ & $10.5 \pm 2.27$ & $17.4 \pm 2.31$ & $17.1 \pm 2.14$ \\
\hline
\end{tabular}

${ }^{\mathrm{ab}}$ Means in the same row with different superscripts differ $(P \leq 0.05)$ (breeds).

The percentage muscle, fat or bone of the retail cuts did not differ $(P>0.05)$ between the $\mathrm{D}$ and SAMM (Table 2). With the exception of the rib, the retail cuts of the NA had a lower $(P \leq 0.05)$ percentage meat compared to the retail cuts of the D or SAMM (Table 2). The observed breed difference was particularly striking in the most expensive loin cut, where the NA contained substantially less meat ( $44.9 \pm$ $1.29 \% ; P \leq 0.05)$ than both the D $(52.8 \pm 1.45 \%)$ and the SAMM $(50.5 \pm 1.92 \%)$. The percentage of meat in the leg of the NA $(61.4 \pm 0.88 \%)$ was also lower $(P \leq 0.05)$ than the $\mathrm{D}(68.0 \pm 1.00 \%)$ leg cut, but compared favourably $(P>0.05)$ to the SAMM $(65.3 \pm 1.32 \%)$ leg cut. The shoulder of the NA $(45.3 \pm 1.18 \%)$ had a lower $(P \leq 0.05)$ percentage of meat than that of the $\mathrm{D}(50.3 \pm 1.41 \%)$. The SAMM was intermediate and not significantly $(P>0.05)$ different from either of the other breeds for this cut (Table 2). This is according to expectations, as the late maturing NA will have a lower percentage muscle than the early maturing $\mathrm{D}$ at the same chronological age and should be similar to the late maturing SAMM with regards to meat yield.

Fat content of the different cuts were the only trait where no differences between the three breeds were found (Table 2), indicating that none of the breeds have reached maturity and that the fattening phase has not yet set in (Berg \& Butterfield, 1968).

Even though no differences for percentage bone were found on comparison of the entire carcass (Table 1), differences were found on analysis of the separate retail cuts. In comparison with both the D and SAMM, the NA contained a higher $(P \leq 0.05)$ percentage of bone in all of the retail cuts (Table 2$)$. Again, this is according to expectations, as the late maturing NA should have a higher percentage bone than the early maturing $\mathrm{D}$ at the same chronological age. However, it was expected that the NA would be more similar to the late maturing SAMM. When considering the results it is important to bear in mind that no selection for economically important traits have been done on the NA and that the breed has not been genetically bred for meat production as both D and SAMM were (Epstein, 1960; De Waal \& Combrinck, 2000; Sheridan et al., 2003; Buduram, 2004).

Most of the differences in physical composition between the D and NA can be qualified by the fact that the D is early maturing and the NA late maturing (Epstein, 1960; Webb \& Casey, 1995). Carcass 
composition can be described as the ratio to which the main tissues (muscle, fat, and bone) are found in a sheep carcass (Berg \& Butterfield, 1968). Breed, age, nutrition and weight all affect the development of these tissues and their ratio relative to carcass weight (Berg \& Butterfield, 1968). Development of different tissues/limbs/organs takes place in different stages, broadly sequenced chronologically as: central nervous system; bone; muscle; fat (Lawrie \& Ledward, 2006). Although these stages progress simultaneously, the rate of development of each stage depends on its role in and importance to the survival of the animal.

Table 2 Least square means ( \pm SE) of percentage muscle-fat-bone yield of NA, D and SAMM retail cuts

\begin{tabular}{|c|c|c|c|c|}
\hline \multirow{2}{*}{ Yield } & \multirow{2}{*}{ Cut } & \multicolumn{3}{|c|}{ Breed } \\
\hline & & NA (n = 13) & $\mathrm{D}(\mathrm{n}=10)$ & $\operatorname{SAMM}(\mathrm{n}=6)$ \\
\hline \multirow{4}{*}{ Percentage Meat } & Leg & $61.4^{\mathrm{b}} \pm 0.88$ & $68.0^{\mathrm{a}} \pm 1.00$ & $65.3^{\mathrm{ab}} \pm 1.32$ \\
\hline & Loin & $44.9^{b} \pm 1.29$ & $52.8^{\mathrm{a}} \pm 1.45$ & $50.5^{\mathrm{a}} \pm 1.92$ \\
\hline & Rib & $56.7 \pm 2.41$ & $63.1 \pm 2.72$ & $58.3 \pm 3.60$ \\
\hline & Shoulder & $45.3^{b} \pm 1.18$ & $50.3^{\mathrm{a}} \pm 1.40$ & $49.0^{\mathrm{ab}} \pm 1.76$ \\
\hline \multirow{4}{*}{ Percentage Fat } & Leg & $9.27 \pm 0.70$ & $8.50 \pm 0.79$ & $9.5 \pm 1.05$ \\
\hline & Loin & $14.2 \pm 1.17$ & $17.7 \pm 1.33$ & $16.5 \pm 1.76$ \\
\hline & Rib & $14.4 \pm 2.40$ & $18.5 \pm 2.71$ & $19.3 \pm 3.58$ \\
\hline & Shoulder & $12.5 \pm 1.14$ & $16.1 \pm 1.36$ & $13.5 \pm 1.71$ \\
\hline \multirow{4}{*}{ Percentage Bone } & Leg & $29.3^{\mathrm{a}} \pm 0.70$ & $23.5^{b} \pm 0.79$ & $25.2^{\mathrm{b}} \pm 1.04$ \\
\hline & Loin & $40.8^{\mathrm{a}} \pm 1.20$ & $29.6^{\mathrm{b}} \pm 1.35$ & $33.0^{\mathrm{b}} \pm 1.79$ \\
\hline & Rib & $28.9^{\mathrm{a}} \pm 0.92$ & $18.4^{\mathrm{b}} \pm 1.04$ & $22.4^{\mathrm{b}} \pm 1.38$ \\
\hline & Shoulder & $42.2^{\mathrm{a}} \pm 0.99$ & $33.7^{\mathrm{b}} \pm 1.12$ & $37.5^{\mathrm{b}} \pm 1.48$ \\
\hline Average carcass weight (kg) & & $10.5 \pm 2.27$ & $17.4 \pm 2.31$ & $17.1 \pm 2.14$ \\
\hline
\end{tabular}

${ }^{\text {ab }}$ Means in the same row with different superscripts differ $(P \leq 0.05)$.

According to Lawrie \& Ledward (2006), the entire development process takes place in a shorter timespan for early maturing breeds than for late maturing breeds, indicating that the muscle : bone ratio of an early maturing breed should be higher than that of a late maturing breed at the same chronological age, until physiological maturity is reached by both. Furthermore, bone development takes preference over muscle and fat development (Lawrie \& Ledward, 2006). The percentage of bone in the carcass will be higher at birth than at any other given time and the percentage of fat the lowest (Berg \& Butterfield, 1968). As development continues the ratio of bone to carcass weight decreases while muscle ratio increases, and thus the muscle to bone ratio increases with an increase in carcass weight. Muscle tissue has the highest growth rate between birth and maturity (Berg \& Butterfield, 1968). As maturity is reached the percentage of muscle to carcass weight will start to decrease as the percentage of fat starts to increase (fattening phase) (Berg \& Butterfield, 1968). Thus it can be deduced that differences in the physical composition of certain cuts will be present, as influenced by age and degree of fatness (Lawrie \& Ledward, 2006).

Only the rib-cut of the NA does not follow the expected pattern of comparison between late/early maturing breeds. Although NA contains a higher percentage of bone than the D and the SAMM (Table 2), it compares well in terms of percentage meat with the other breeds. Differences in genetics and the size of cuts should be recognised here as possible explanation (Epstein, 1960; Berg \& Butterfield, 1968). Buduram (2004) noted that the NA breed shows very little polymorphism and is the most genetically different from the other indigenous and developed breeds, including the D.

Mason \& Maule (1960) have noted that a $20 \mathrm{~kg}$ NA carcass can be reached at 12 - 18 months of age. Together with the differences in percentage of meat (loin cut) and bone yield between the NA and also late maturing SAMM, it could be indicative of an even longer development cycle of the NA carcass. From the high percentage of bone and low percentage of muscle in the NA carcass it can be expected that the NA is 
still growing bone and has not fully started with muscle development when slaughtered in the present study (Berg \& Butterfield, 1968; Lawrie \& Ledward, 2006).

\section{Conclusion}

Climate change may constrain the contribution of commercial sheep breeds such as the D and SAMM in future, as constraints on food sources limit growth and development of animals, especially when not adapted to harsh conditions. With consumer preferences and purchase intent changing towards food products beneficial to health, lean meat is sought after thereby creating the possibility of marketing the leaner meat of the NA as such. The NA did not compare well with the D for meat yield, but despite its carcass being smaller and containing a higher percentage bone than the SAMM carcass, it performed better against the SAMM in terms of meat yield. Future research involving crossbreeding may elucidate the possibility of combining the hardiness of the NA with early maturity in the D and meat quality in the SAMM.

\section{Acknowledgements}

The authors would like to thank the Technology and Human Resources for Industry Programme (THRIP) and the University of Stellenbosch for their financial assistance. We would also like to thank the employees of Nortier Experimental farm and Roelcor Abattoir - Malmesbury and as well as Katryn Schoon for their contribution to the success of the project.

\section{References}

Acocks, J.P.H., 1988. Veld types of South Africa. Mem. bot. Surv. S. Afr. No. 28, Government Printer, Pretoria, South Africa. pp. 11-113.

Berg, R.T. \& Butterfield, R.M., 1968. Growth patterns of bovine muscle, fat and bone. Anim Sci. 27, 611-619.

Biesalski, H-K., 2005. Meat as a component of a healthy diet - are there any risks or benefits if meat is avoided in the diet? Meat Sci. 70, 509-524.

Brand, T.S., 2000. Grazing behaviour and diet selection by Dorper sheep. Small Rumin. Res. 36, 147-158.

Buduram, P., 2004. Genetic characterization of Southern African sheep breeds using DNA markers. MSc (Agric) thesis, University of the Free State, Bloemfontein, South Africa.

Cloete, J.J.E., Cloete, S.W.P., Oliver, J.J. \& Hoffman, L.C., 2005. Terminal crossbreeding of Dorper ewes to Ile de France, Merino land sheep and SA Mutton Merino sires: Ewe production and lamb performance. Small Rumin. Res. 69, 28-35.

Cloete, S.W.P. \& Olivier, J.J., 2010. South African Industry. In: The International Sheep and Wool Handbook. Ed. Cottle, D.J., Nottingham University Press, Nottingham. England. pp. 95-112.

DAFF, 2012. Abstract of Agricultural Statistics 2012. Department of Agriculture, Forestry and Fisheries, South Africa. http://www.nda.agric.za/docs/statsinfo/Ab2012.pdf 27 Julie 2012.

De Waal, H.O. \& Combrinck, W.J., 2000. The development of the Dorper, its nutrition and a perspective of the grazing ruminant on veld. Small Rumin. Res. 36, 103-117.

Epstein, H., 1960. History and origin of the Ronderib and Namaqua Afrikaner sheep. Z Tierz Zuchtungsbio. 74, 267-292.

FAO, 2012. Food Outlook 2012. EC-FOA Food Security Programme. Food and Agriculture Organization of the United Nations.

http://www.foodsecuritylink.net/index.php?option=com_k2\&view=item\&id=509:fao-food-outlookmay-2012\&Itemid=2 4 August 2012.

Higgs, J.D., 2000. The changing nature of red meat: 20 years of improving nutritional quality. Trends Food Sci. Technol. 11, 85-95.

Hoffman, L.C., Muller, M., Cloete, S.W.P. \& Schmidt, D., 2003. Comparison of six crossbred lamb types: sensory, physical and nutritional meat quality characteristics. Meat Sci. 65, 1265-1274.

Lawrie, R.A. \& Ledward, D.A., 2006. Lawrie’s Meat Science. ( $7^{\text {th }}$ ed.). Woodhead Publ. Ltd., Cambridge. England. pp. 15-40.

Mason, I.L. \& Maule, J.P., 1960. The Indigenous Livestock of Eastern and Southern Africa. Robert Cunningham \& Sons Ltd., Alva, Great Britain. pp. 101-102. 
Reiser, R. \& Shorland, F.B., 1990. In: Advances in Meat Research. (Vol. 6). Ed. Pearson, A.M. \& Dutson, T.R., Elsevier Applied Science, London, UK. pp. 13.

SAS, 2002. Statistical Analysis Systems user’s guide (Version 8, Volume 2). SAS Institute Inc., Raleigh, North Carolina, USA.

Sheridan, R., Hoffman, L.C. \& Ferreira, A.V., 2003. Meat quality of Boer goat kids and Mutton Merino lambs 1. Commercial yields and chemical composition. Anim. Sci. 76, 63-71.

Turpie, J., Winkler, H., Spalding-Fecher, R. \& Midgley, G., 2002. Economic Impacts of Climate Change in South Africa: A preliminary analysis of unmitigated damage costs. Southern Waters Ecological Research Consulting and Energy and Development Research Centre. University of Cape Town, Cape Town, Cape Town, South Africa. pp. 7.

Van der Westhuizen, E.J., 2010. The effect of slaughter age on the lamb characteristics of Merino, South African Mutton Merino and Dorper lambs. MSc (Agric) thesis, University of Stellenbosch, Stellenbosch, South Africa.

Warriss, P.D., 2000. Meat Science: An Introductory Text. CABI Publishing, New York, USA. pp. 4-7, 106-130.

Webb, E.C. \& Casey, N.H., 1995. Genetic differences in fatty acid composition of subcutaneous adipose tissue in Dorper and SA Mutton Merino wethers at different live weights. Small Rumin. Res. 18, 81-88.

Webb, E.C., Casey, N.H. \& Van Niekerk, W.A., 1994. Fatty acids in the subcutaneous adipose tissue of intensively fed SA Mutton Merino and Dorper wethers. Meat Sci. 38, 123-131.

Wood, J.D., Richardson, R.I., Nute, G.R., Fisher, A.V., Campo, M.M., Kasapidou, E., Sheard, P.R. \& Enser, M., 2003. Effects of fatty acids on meat quality: a review. Meat Sci. 66, 21-32. 